\title{
Phytochemical Extraction and Antioxidant Studies of Cassia Angustifolia Extracts
}

\author{
Suresh D \\ Department of Chemistry, UCS, Tumkur University, Tumakuru, Karnataka, India PIN-572 103 \\ Email:pbdsuresh@gmail.com
}

\begin{abstract}
The present investigation aims at the extraction, phytochemical constituent analysis and antioxidant activity analysis of Cassia angustifolia. The solvents such as water, Ethanol-water, Ethyl acetate and Methanol were utilized to optimize extraction process arrive at extract with higher yields and better antioxidant potency. It was observed that water provides highest yield among all the solvents $(20.7 \%)$. Ethanol water also yielded almost same extraction yield $(20.4 \%)$. Whereas, methanol provided $17 \%$ and ethyl acetate about $11 \%$ of the yield. It was observed that the methanol extract was found to have highest percent of polyphenols of $30 \%$ and Ethyl acetate extract was found to have about $23 \%$. It was found that water-ethanol extract was proved to have highest contents of flavonoids of $15 \%$. This is followed by water extract $(13 \%)$. The results of DPPH free radical inhibitory activity studies indicate that water and ethyl acetate extracts were found to exhibit $\mathrm{IC}_{50}$ value of $274 \mu \mathrm{g} / \mathrm{ml}$ and $288 \mu \mathrm{g} / \mathrm{ml}$ respectively. Both the extracts have proved to be moderately active at inhibiting the activity of DPPH. The other extract such as ethanol - water and methanol extracts were proved to be have $\mathrm{IC}_{50}$ values of $369 \mu \mathrm{g} / \mathrm{ml}$ and $380 \mu \mathrm{g} / \mathrm{ml} \mathrm{respectively.} \mathrm{Thus,} \mathrm{the} \mathrm{present}$ investigation has provided crucial information on the phytochemical contents and antioxidant activities of extracts of Cassia angustifolia. The results warrant for further studies in this direction leading to isolation and characterization of individual molecules responsible for the antioxidant activities of the extracts from very common plants that are available in our neighborhood.
\end{abstract}

Index Terms- Cassia angustifolia, Phytochemical extraction, antioxidant studies

\section{INTRODUCTION}

An antioxidant is a molecule capable of inhibiting the oxidation of other molecules. Oxidation is a chemical reaction that transfers electrons from a substance to an oxidizing agent. Oxidation reactions can produce free radicals. In turn, these radicals can start chain reactions. When the chain reaction occurs in a cell, it can cause damage or death. When the chain reaction occurs in a purified monomer, it produces a polymer resin, such as a plastic, a synthetic fiber, or an oil paint film. Antioxidants terminate these chain reactions by removing free radical intermediates, and inhibit other oxidation reactions. They do this by being oxidized themselves, so antioxidants are often reducing agents such as thiols, ascorbic acid or polyphenols.

Antioxidant compounds in food play an important role as a health protecting factor. Scientific evidence suggests that antioxidantsreduce the risk for chronic diseases including cancer and heart disease. Primary sources of naturally occurring antioxidants are whole grains, fruits and vegetables. Plant sourced food antioxidants like vitamin $\mathrm{C}$, vitamin $\mathrm{E}$, carotenes, phenolic acids, phytate and phyto-estrogens have been recognized as havingthe potential to reduce disease risk. Most of the antioxidant compounds in a typical diet are derived from plant sources and belong to various classes of compounds with a wide variety of physical and chemical properties. Some compounds, such as gallates, have strong antioxidant activity, while others, such as the mono-phenols are weak antioxidants. There are a number of clinical studies suggesting that the antioxidants in fruits, vegetables, tea and red wine are the main factors for the observed efficacy of these foods in reducing the incidence of chronic diseases including heart disease and some cancers. The free radical scavenging activity of antioxidants in foods has been substantially investigated and reported in the literature by Miller and Rigelhofet.al $(1,2)$.

Although oxidation reactions are crucial for life, they can also be damaging; hence, plants and animals maintain complex systems of multiple types of antioxidants, such as glutathione, vitamin $\mathrm{C}$, and vitamin $\mathrm{E}$ as well as enzymes such as catalase, superoxide dismutase and various peroxidases. Low levels of antioxidants, or inhibition of the antioxidant enzymes, cause oxidative stress and may damage or kill cells. Antioxidants are classified into two broad divisions, depending on whether they are soluble in water (hydrophilic) or in lipids (hydrophobic). In general, water-soluble antioxidants react with oxidants in the cell cytosol and the blood plasma, while lipidsoluble antioxidants protect cell membranes from lipid peroxidation (3). These compounds may be synthesized in the body or obtained from the diet (4). The different antioxidants are present at a wide range of concentrations in body fluids and tissues, with some such as glutathione or ubiquinone mostly present within cells, while others such as uric acid are more evenly distributed. Some antioxidants are only found in a few organisms and these compounds can be important in pathogens and can be virulence factors. Antioxidants are used as food additives to help guard against food deterioration. Exposure to oxygen and sunlight are the two main factors in the oxidation of food, so food is preserved by keeping in the dark and sealing it in 


\section{International Journal of Research in Advent Technology, Vol.7, No.4, April 2019 E-ISSN: 2321-9637 \\ Available online at www.ijrat.org}

containers or even coating it in wax, as with cucumbers. However, as oxygen is also important for plant respiration, storing plant materials in anaerobic conditions produces unpleasant flavors and unappealing colors (5). Consequently, packaging of fresh fruits and vegetables contains an $\sim 8 \%$ oxygen atmosphere. Antioxidants are an especially important class of preservatives as, unlike bacterial or fungal spoilage, oxidation reactions still occur relatively rapidly in frozen or refrigerated food (6). These preservatives include natural antioxidants such as ascorbic acid and tocopherols, as well as synthetic antioxidants such as propyl gallate, tertiary butyl hydroquinone, butylated hydroxyl anisole and butylated hydroxyl toluene (7). The most common molecules attacked by oxidation are unsaturated fats; oxidation causes them to turn rancid (8). Since oxidized lipids are often discolored and usually have unpleasant tastes such as metallic or sulfurous flavors, it is important to avoid oxidation in fat-rich foods. Thus, these foods are rarely preserved by drying; instead, they are preserved by smoking, salting or fermenting. Even less fatty foods such as fruits are sprayed with sulfurous antioxidants prior to air drying. Oxidation is often catalyzed by metals, which is why fats such as butter should never be wrapped in aluminium foil or kept in metal containers. Some fatty foods such as olive oil are partially protected from oxidation by their natural content of antioxidants, but remain sensitive to photo oxidation (9). Antioxidant preservatives are also added to fat-based cosmetics such as lipstick and moisturizers to prevent rancidity. Antioxidants are frequently added to industrial products. A common use is as stabilizers in fuels and lubricants to prevent oxidation, and in gasolines to prevent the polymerization that leads to the formation of enginefouling residues (10). In 2007, the worldwide market for industrial antioxidants had a total volume of around 0.88 million tons. This created revenue of 3.7 billion US-dollars.

A polyphenol antioxidant is a type of antioxidant containing a polyphenolic substructure. Numbering over 4,000 distinct species, these compounds have antioxidant activity in vitro but are unlikely to have antioxidant roles in vivo (11). Rather, they may affect cell-to-cell signaling, receptor sensitivity, inflammatory enzyme activity or gene regulation (12). Polyphenols are the most abundant antioxidants in the diet. Their total dietary intake could be as high as $1 \mathrm{~g} / \mathrm{d}$, which is much higher than that of all other classes of phytochemicals and known dietary antioxidants. For perspective, this is $\sim 10$ times higher than the intake of vitamin $\mathrm{C}$ and 100 times higher than the intakes of vitamin $\mathrm{E}$ and carotenoids (13). Their main dietary sources are fruits and plant-derived beverages such as fruit juices, tea, coffee, and red wine. Vegetables, cereals, chocolate, and dry legumes also contribute to the total polyphenol intake. Despite their wide distribution in plants, the health effects of dietary polyphenols have come to the attention of nutritionists only rather recently. Until the mid-1990s, the most widely studied antioxidants were antioxidant vitamins, carotenoids, and minerals. Current evidence strongly supports a contribution of polyphenols to the prevention of cardiovascular diseases, cancers, and osteoporosis and suggests a role in the prevention of neurodegenerative diseases and diabetes mellitus (14). Flavonoids (specifically flavanoids such as the catechins) are "the most common group of polyphenolic compounds in the human diet and are found ubiquitously in plants"(15). Flavonols, the original bioflavonoids such as quercetin, are also found ubiquitously, but in lesser quantities. The widespread distribution of flavonoids, their variety and their relatively low toxicity compared to other active plant compounds (for instance alkaloids) mean that many animals, including humans, ingest significant quantities in their diet. Preliminary research indicates that flavonoids may modify allergens, viruses, and carcinogens, and so may be biological "response modifiers". In vitro studies show that flavonoids also have anti-allergic, anti-inflammatory (16), antimicrobial $(17,18)$ and anti-cancer activities (19).

Cassia angustifolia, more commonly known as senna, is an herb with laxative qualities. The medical uses of Cassia angustifolia include the treatment of intestinal conditions such as constipation, irritable bowel syndrome (IBS) and hemorrhoids. It also can be used to treat hemorrhoids or as a laxative. A native plant of Africa, Cassia angustifolia's use as a laxative can be traced to the ninth century.

Senna leaves contain the glycosides: sennosides A, B, $\mathrm{C}$, and $\mathrm{D}$, aloe-emodin-dianthrone-diglucoside, and a naphthalene glycoside: tinnevellin glucoside. Sennosides A and B are both hydrolyzed to give 2 molecules of glucose and the aglycones sennidin A and $\mathrm{B}$, sennidin A is dextrorotatory and B is its mesoform. Senna also contains another glucoside kaempferin, sterols, mucilage, calcium oxalate and resin (20). Other constituents include cathartic acid, camphene, sennacrol and senna-picrin (21). Senna is included in the essential drugs list (EDL) of the world health organization (WHO) (22), popularly known as Senna, is a valuable plant drug in Ayurveda and modern system of medicine for the treatment of constipation Cultivation of Senna does not require much expenditure on irrigation, manuring, pesticides, protection and other pre- and postharvest care. The Sennosides had been extracted from Senna leaves, stems, pods, buds and flowers but no Sennosides were found in the seeds (23). The senna plant is a small shrub belonging to the Caesalpiniaceae family. Incidentally, senna also known as Alexandrina senna, and $C$. angustifolia that is also called the Tinnevelly senna. While the first variety of senna is found along the Nile River in Egypt and Sudan, the second type is widely cultivated in southern and eastern parts of India. It is cultivated traditionally over 10,000 ha in semi-arid lands in coastal districts of Tirunelvelli, Ramnathapuram and Madurai in Tamil Nadu. The plant bears grayish-green colored leaves that are very delicate. In addition, the herb bears oblong shaped pods 


\section{International Journal of Research in Advent Technology, Vol.7, No.4, April 2019 E-ISSN: 2321-9637 \\ Available online at www.ijrat.org}

or fruit cases. The leaves as well as the pods of the plant have therapeutic use (24).

Natural antioxidants such as $\alpha$-tocopherol and Lascorbicacid are widely used because they are seen as being safer and causing fewer adverse reactions, but their antioxidant activities are, however, lower than those of synthetic antioxidants such as butylated hydroxyl anisole (BHA) and butylated hydroxyl toluene (BHT). Hence, the need exists for safe, economic antioxidants with high activity from natural sources to replace these synthetic chemicals. The antioxidant compounds present in edible plants have recently been promoted as food additives because they display little or no toxic side effects.

The number of antioxidant compounds synthesized by plants as secondary products, mainly phenolics, serving in plant defense mechanisms to counteract ROS in order to survive, is currently estimated to be between 4000 and 6000 (20). A direct relationship has been found between the content of total phenolics and antioxidant capacity of plants (21). In fact, to counteract deleterious action of ROS, phenolic compounds, naturally distributed in plants, are effective (22) Because purified phenolic compounds are difficult to obtain and because extracts sometimes have better antioxidant activities than those of pure molecules, there is a growing interest for the use of plant extracts (24). To find new natural sources of active compounds, we studied the antioxidant potential of different extracts of Cassia angustifolia.

\section{MATERIALS \& METHODS}

1, 1 - Diphenyl - 2 - picrylhydrazyl was procured from Sigma-Aldrich India Company. Ascorbic acid, Gallic acid, Vanillin, Phloroglucinol and Methanol were purchased from S. D. Fine Chemicals. All other solvents are of AR grade and distilled before use. Distilled water was employed for all the experiments. Cassia angustifolia leaves were sourced from Amruth kesari Depot Bangalore. The leaves were shade dried and powdered into 100 mesh size and was stored at room temperature in an airtight container.

Reflux Extraction: Hot water extract preparation: Hot water soluble polar compounds can be extracted by this method. In this case, cold water insoluble compounds but soluble in hot water can be extracted. 1: 10 proportion of material to solvent was taken for extraction and the extraction is carried out at boiling temperature of water $\left(100^{\circ} \mathrm{C}\right)$ with a reflux arrangement for 3 hours with constant stirring and the extract is filtered and centrifuged to remove any un-dissolved material. The extract is then concentrated to $1 / 5$ volume on the concentrator and dried completely. Thus prepared extract is stored in airtight bottles.

80\% Ethanol extract preparation: Ethanol-water soluble polar compounds can be extracted by this method while the proteins and polysaccharides get precipitated. Here too, 1: 10 proportion of material to solvent was taken for extraction and the extraction is carried out at boiling temperature of ethanol $\left(65^{\circ} \mathrm{C}\right)$ with a reflux arrangement for 3 hours with constant stirring and the extract is filtered and centrifuged to remove any un-dissolved material. The extract is then concentrated to dryness. Thus prepared extract is stored in airtight bottles.

Methanol extracts preparation: Methanol soluble polar compounds can be extracted by this method while the proteins and polysaccharides get precipitated. Here too, 1: 10 proportion of material to solvent was taken for extraction and the extraction is carried out at boiling temperature of Methanol with a reflux arrangement for 3 hours with constant stirring and the extract is filtered and centrifuged to remove any un-dissolved material. The extract is then concentrated to dryness. Thus prepared extract is stored in airtight bottles.

Ethyl acetate extracts preparation: Ethyl acetate soluble compounds can be extracted by this method while the proteins and polysaccharides get precipitated. Here also, 1: 10 proportion of material to solvent was taken for extraction and the extraction is carried out at boiling temperature of Ethyl acetate with a reflux arrangement for 3 hours with constant stirring and the extract is filtered and centrifuged to remove any undissolved material. The extract is then concentrated to dryness. Thus prepared extract is stored in airtight bottles.

DPPH Assay: 1, 1 - Diphenyl - 2 - picrylhydrazyl (Oxidized form) is a stable free radial with Purple color. In the presence of an antioxidant which can donate an electron to DPPH, the purple color which is typical to free DPPH radical decays, and the change in absorbance at $520 \mathrm{~nm}$ is followed which can be measured spectrophotometrically. Dissolved $39.4 \mathrm{mg}$ of DPPH in $100 \mathrm{ml}$ of methanol to get concentration of $1 \mathrm{mM}$ stock.Stored in dark bottle at $4^{\circ} \mathrm{C}$ until its use. The working concentration of DPPH in the assay was $0.14 \mathrm{mM}$. Methanol $(50 \%)$ was prepared by diluting methanol 1:1 with de-ionized water. Ascorbic acid standard Stock I (Conc. 200 $\square \mathrm{g} / \mathrm{ml}$ ) was prepared by dissolving $2 \mathrm{mg}$ of ascorbic acid and make up to a volume of $10 \mathrm{ml}$ with de-ionized water. For making standard graph of ascorbic acid 2, 4, 6, 8, 10 $\square \mathrm{g} / \mathrm{ml}$ concentration range was used. The DPPH assay was carried out by using modified method of BrandWilliams (29), in brief to a $860 \square 1$ of $50 \%$ methanol / ascorbic acid / test sample with various concentrations, added $140 \square 1$ of $1 \mathrm{mM}$ DPPH, mixed and incubated at $37^{\circ} \mathrm{C}$ for $30 \mathrm{~min}$. Read the absorbance at $520 \mathrm{~nm}$ against $50 \%$ methanol blank by spectrophotometer, a control reaction is carried out by without test sample addition. Colour Correction contains the same concentration of the test sample in methanol without DPPH. The antioxidant activity was measured with reference to the standard ascorbic acid absorbance values. The actual absorbance is taken as the absorbance difference of the control and the test sample and $\mathrm{IC}_{50}$ values were determined.

Polyphenol Assay: Phenolic compounds in alkaline condition (sodium carbonate) dissociate to yield a 


\section{International Journal of Research in Advent Technology, Vol.7, No.4, April 2019 E-ISSN: 2321-9637 \\ Available online at www.ijrat.org}

proton and phenolate anion, which is capable of reducing Folinciocalteu reagent. FC reagent is an oxidizing agent comprised of heteropolyphosphotungstate-molybdate. Sequences of one or two electron reduction reaction lead to blue color species. The blue colored product is a mixture of the $1-$, $2-, 4-$, and 6-electron reduction products in the tungstate series $\mathrm{P}_{2} \mathrm{~W}_{18} \mathrm{O}_{62}{ }^{-7}$ to $\mathrm{H}_{4} \mathrm{P}_{2} \mathrm{~W}_{18} \mathrm{O}_{62}{ }^{-8}$ and the 2-, 4- and 6electron reduction products in the molybdate series $\mathrm{H}_{2} \mathrm{P}_{2} \mathrm{Mo}_{18} \mathrm{O}_{62}{ }^{-6}$ to $\mathrm{H}_{6} \mathrm{P}_{2} \mathrm{Mo}_{18} \mathrm{O}_{62}{ }^{-6}$. Folinciocalteu reagent $(0.1 \mathrm{~N})$ was prepared by diluting 1:20 with commercially available FC Reagent with distilled water to get the required concentration. Sodium carbonate $(7.5 \%)$ was prepared by dissolving $7.5 \mathrm{gm}$ of sodium carbonate in $100 \mathrm{ml}$ of de-ionized water. Gallic acid (standard) stock I (Conc. $0.1 \mathrm{mg} / \mathrm{ml}$ ) was prepared by dissolving $1 \mathrm{mg}$ of gallic acid in $10 \mathrm{ml}$ with $50 \%$ Methanol. For making standard graph of Gallic acid concentration range of 2 $20 \square \mathrm{g} / \mathrm{ml}$ was used. The assay was carried out by Using Singleton, V., Rossi, J. A. Jr, method (30), In brief, to a $200 \mu \mathrm{l}$ of $50 \%$ Methanol / Standard / test sample with various concentrations, added $1000 \mu \mathrm{l}$ of FC reagent, mixed and incubated at RT for 5min. added $800 \mu \mathrm{l}$ of $7.5 \%$ sodium carbonate, mixed and incubated at RT for 30 minutes. Read the absorbance at $750 \mathrm{~nm}$ against blank by spectrophotometer, Color correction was given with the same concentration of the test sample in $50 \%$ Methanol without FC reagent.

Flavonoids Assay: Vanillin, an aromatic aldehyde condenses with the flavon-3-ols and oligomers to form soluble pigments in acidic medium with an absorbance maximum at $500 \mathrm{~nm}$, which can be detected by UV-VIS spectrophotometer. Vanillin Reagent (1\%) was prepared by dissolving $1 \mathrm{gm}$ of crystallized vanillin in $100 \mathrm{ml}$ of $70 \%$ Conc. $\mathrm{H}_{2} \mathrm{SO}_{4}$ (Prepared fresh). Conc. $\mathrm{H}_{2} \mathrm{SO}_{4}(70 \%)$ was prepared by diluting $70 \mathrm{ml}$ on Conc. $\mathrm{H}_{2} \mathrm{SO}_{4}$ in $100 \mathrm{ml}$ De-ionized water. Methanol (50\%) was prepared by diluting 1:1 with de-ionized water.

Phloroglucinol (standard) stock I (Conc. 1mg/ml): Dissolved $10 \mathrm{mg}$ of Phloroglucinol and made up to a volume of $10 \mathrm{ml}$ with $50 \%$ Methanol, Then centrifuge at $12,000 \mathrm{rpm}$ for10min. Stock II: Diluted to a conc. to yield $0.1 \mathrm{mg} / \mathrm{ml}$ with $50 \%$ Methanol. For making standard graph of Phloroglucinol, $1-10 \square \mathrm{g} / \mathrm{ml}$ concentration range was used. The Flavonoid assay was carried out by using Swain, T. and Hillis, W. E method (31). In brief, to a $400 \mu$ l of distilled water / Positive control / test sample with various concentrations, added $800 \mu \mathrm{l}$ of $1 \%$ vanillin reagent, mixed and incubated at RT for 15 minutes. Read the absorbance at $500 \mathrm{~nm}$ against blank by spectrophotometer. Color correction was given with the same concentration of the test sample in distilled water without vanillin reagent. The Flavonoid content in the phytoextracts was measured with reference to the standard Gallic acid values.

\section{RESULTS \& DISCUSSION}

Extraction Yields:

\begin{tabular}{|c|l|c|}
\hline Sl. No. & Extraction Solvent & \% Yield \\
\hline 1. & Water & $\mathbf{2 0 . 7 0}$ \\
\hline 2. & $\begin{array}{l}\text { Ethanol - Water } \\
(80: 20)\end{array}$ & $\mathbf{2 0 . 4 2}$ \\
\hline 3. & Methanol & $\mathbf{1 7 . 8 7}$ \\
\hline 4. & Ethyl acetate & $\mathbf{1 0 . 8 0}$ \\
\hline
\end{tabular}

Table - 1: The percentage yield of the extract with various solvents\& methods.

The solvents such as water, Ethanol-water, Ethyl acetate and Methanol were utilized to optimize extraction process so as to arrive at extract with higher yields and better antioxidant potency. It was observed that water provides highest yield among all the solvents. Water with ethanol was also selected as the extraction solvents since both are commonly used in the food industry in a variety of ways. Ethanol water also yielded almost same extraction yield. Whereas methanol provided $17 \%$ and ethyl acetate about $11 \%$ of the yield. The extraction yield is highly valued because a low extraction yield means a lower productivity despite high antioxidant potency. The extraction yields were expressed in terms of the solid content in the dried product per soluble solid content in plant material used on a dry basis. Table - 1 shows the extraction yields of the various extracts from plant materials. Despite the low values obtained for the extraction yields, the antioxidant contents found were good, indicating that the extraction was efficient. Nevertheless, a relationship between the extracted mass and the corresponding total phenolics and flavonoids were not observed in all cases. Most of the phenolic or polyphenolic compounds in nature have antioxidative activities, e.g. tocopherols, flavonoids and derivatives of cinnamic acid, phosphatidic and other organic acids.

Polyphenol Content:

\begin{tabular}{|c|l|c|}
\hline Sl. No. & Extraction Solvent & Reflux Extract \\
\hline 1. & Water & $14.5 \%$ \\
\hline 2. & $\begin{array}{l}\text { Ethanol - Water } \\
(80: 20)\end{array}$ & $15.6 \%$ \\
\hline 3. & Methanol & $30.0 \%$ \\
\hline 4. & Ethyl acetate & $23.2 \%$ \\
\hline
\end{tabular}

Table - 2: The polyphenol content of the extracts with various solvents.

Polyphenol content was determined by Singleton method. It was observed that the methanol extract was found to have highest percent of polyphenols of $30 \%$ and Ethyl acetate extract was found to have about $23 \%$. Hence it can be concluded that both methanol, ethyl acetate extract could be highly potential in terms of health beneficial physiological effects. The polyphenol contents of other extracts such as water and Ethanolwater extracts have comparably less Polyphenol contents. 
Flavonoids Content:

\begin{tabular}{|c|l|c|}
\hline Sl. No. & Extraction Solvent & Reflux Extract \\
\hline 1. & Water & $13.33 \%$ \\
\hline 2. & $\begin{array}{l}\text { Ethanol }- \text { Water } \\
(80: 20)\end{array}$ & $15.0 \%$ \\
\hline 3. & Methanol & $12.5 \%$ \\
\hline 4. & Ethyl acetate & $14.25 \%$ \\
\hline
\end{tabular}

Table - 3: The Flavonoid content of the extracts with various solvents.

It is evident from above data that water ethanol extract was proved to have highest contents of flavonoids of $15 \%$. This is followed by water extract which is of $13 \%$. Other extracts such as methanol and ethyl acetate also shown to have considerably higher percentage of flavonoids. The water extract could be potent extract in terms of flavonoid contents which could elicit very useful health beneficial activities.

\section{DPPH Activity:}

\begin{tabular}{|c|l|c|}
\hline $\begin{array}{c}\text { Sl. } \\
\text { No. }\end{array}$ & \multicolumn{1}{|c|}{ Extraction Solvent } & $\begin{array}{c}\text { DPPH Activities } \\
\left(\text { IC }_{\mathbf{5 0}}\right)\end{array}$ \\
\hline 1. & Water & $274 \mu \mathrm{g} / \mathrm{ml}$ \\
\hline 2. & $\begin{array}{l}\text { Ethanol }- \text { Water } \\
(80: 20)\end{array}$ & $369 \mu \mathrm{g} / \mathrm{ml}$ \\
\hline 3. & Methanol & $380 \mu \mathrm{g} / \mathrm{ml}$ \\
\hline 4. & Ethyl acetate & $288 \mu \mathrm{g} / \mathrm{ml}$ \\
\hline
\end{tabular}

Table - 4: The DPPH activity of the extracts with various solvents. The $\mathrm{IC}_{50}$ values are expressed in $\mu \mathrm{g} / \mathrm{ml}$

DPPH a stable free radical with a characteristic absorption at $520 \mathrm{~nm}$, was used to study the radical scavenging effects of ethanol extracts. The decrease in absorption is taken as a measure of the extent of radical scavenging. The radical-scavenging activity (RSA) values were expressed as the ratio percentage of sample absorbance decrease and the absorbance of $\mathrm{DPPH}^{\circ}$ solution in the absence of extract at $520 \mathrm{~nm}$. It is observed from the results that water extract was found to exhibit $\mathrm{IC}_{50}$ value of $274 \mu \mathrm{g} / \mathrm{ml}$ and ethyl acetate extract has the $\mathrm{IC}_{50}$ value of $288 \mu \mathrm{g} / \mathrm{ml}$. Both the extracts have proved to be moderately active at inhibiting the activity of DPPH. The other extract such as ethanol - water and methanol extracts were proved to be have $\mathrm{IC}_{50}$ values of $369 \mu \mathrm{g} / \mathrm{ml}$ and $380 \mu \mathrm{g} / \mathrm{ml}$ respectively.

\section{CONCLUSIONS}

The present investigation aims at the extraction, phytochemical constituent analysis and antioxidant activity analysis of Cassia angustifolia. The solvents such as water, Ethanol-water, Ethyl acetate and Methanol were utilized to optimize extraction process arrive at extract with higher yields and better antioxidant potency. It was observed that water provides highest yield among all the solvents (20.7\%). Water with ethanol was also selected as the extraction solvents since both are commonly used in the food industry in a variety of ways. Ethanol water also yielded almost same extraction yield (20.4\%). Whereas, methanol provided $17 \%$ and ethyl acetate about $11 \%$ of the yield.

It was observed that the methanol extract was found to have highest percent of polyphenols of $30 \%$ and Ethyl acetate extract was found to have about $23 \%$. Hence it can be concluded that both methanol, ethyl acetate extract could be highly potential in terms of health beneficial physiological effects. The polyphenol contents of other extracts such as water and Ethanolwater extracts have comparably less Polyphenol contents.

It was found that water-ethanol extract was proved to have highest contents of flavonoids of $15 \%$. This is followed by water extract (13\%). Other extracts such as methanol and ethyl acetate also shown to have considerably higher percentage of flavonoids. The water extract could be potent extract in terms of flavonoid contents which could elicit very useful health beneficial activities.

The results of DPPH free radical inhibitory activity studies indicate that water extract was found to exhibit $\mathrm{IC}_{50}$ value of $274 \mu \mathrm{g} / \mathrm{ml}$ and ethyl acetate extract has the $\mathrm{IC}_{50}$ value of $288 \mu \mathrm{g} / \mathrm{ml}$. Both the extracts have proved to be moderately active at inhibiting the activity of DPPH. The other extract such as ethanol - water and methanol extracts were proved to be have $\mathrm{IC}_{50}$ values of $369 \mu \mathrm{g} / \mathrm{ml}$ and $380 \mu \mathrm{g} / \mathrm{ml}$ respectively.

Thus, the present investigation has provided significant information on the phytochemical contents and antioxidant activities of various solvent extracts of Cassia angustifolia. The results clearly indicate some major findings in the quest of the search for potential antioxidants that can be of very useful to mankind. The results warrant for further studies in this direction leading to isolation and characterization of individual molecules responsible for the antioxidant activities of the extracts from very common plants that are available in our neighborhood.

\section{REFERENCES:}

[1] Miller, H.E., Rigelhof, F., Marquart, L., Prakash, A., and Kanter, M. Cer. Foods World 45(2), 59-63 (2000).

[2] Miller, H.E., Rigelhof, F., Marquart, L., Prakash, A., and Kanter, M. J. Am. Coll. Nutr. 19(3), 312S-319S (2000).

[3] Sies, Helmut. Experimental physiology 82 (2): 291-295(1997).

[4] Vertuani, Silvia; Angusti, Angela; Manfredini, Stefano, Current Pharmaceutical Design 10 (14): 1677-94. (2004).

[5] Kader A, Zagory D, Kerbel E. Crit Rev Food Sci Nutr 28 (1): 1-30. (1989).

[6] Zallen E, Hitchcock M, Goertz G J Am Diet Assoc 67 (6): 552-557. (1975).

[7] Iverson F Cancer Lett 93 (1): 49-54. (1995).

[8] Robards K, Kerr A, Patsalides E. Analyst 113 (2): 213-224. (1988). 
[9] Del Carlo M, Sacchetti G, Di Mattia C, Compagnone D, Mastrocola D, Liberatore L, Cichelli A. J Agric Food Chem 52 (13): 40724079. (2004).

[10] Boozer, Charles E.; Hammond, George S.; Hamilton, Chester E.; Sen, Jyotirindra N Journal of the American Chemical Society 77 (12): 3233-3237. (1955).

[11] Williams RJ, Spencer JP, Rice-Evans C Free Radical Biology \& Medicine 36 (7): 83849(2004)

[12] Virgili F, Marino M Free Radical Biology \& Medicine 45 (9): 1205-16 (2008).

[13] Manach C, Scalbert A, Morand C, Rémésy C, Jimenez L. Am J Clin Nutr;79:727-47

[14] Scalbert A, Williamson G. J Nutr 2000;130:2073S-85S(2004)

[15] Scalbert A, Manach C, Morand C, Rémésy C, Jiménez L. Crit Rev Food Sci Nutr (2007)

[16] Spencer, Jeremy P. E. British Journal of Nutrition 99: ES60-77. (2008).

[17] Yamamoto and Gaynor 107 (2): 135 -- Journal of Clinical Investigation.

[18] Cushnie TPT, Lamb AJ. International Journal of Antimicrobial Agents 26 (5): 343-356. (2005).

[19] Cushnie TPT, Lamb AJ. International Journal of Antimicrobial Agents Epub ahead of print. doi:10.1016/j.ijantimicag..02.014(2011)

[20] William Charles Evans, Trease and Evans. Pharmacognosy, W.B. Saunders, China $15^{\text {th }}$ Edition, 2002, pages: 231-235.

[21] Shokri Ibrahim Saad. Plants of drugs and spices, Dar Al-fikr Al-Arabi, Egypt, 1985, pages: 116 and 117.(Arabic book)

[22] WHO Drug Information bulletin Vol. 13, No 4, 1999

[23] Atal and Kapoor, 1982; Das et al., 2003; Martindale, 1977; Sharma, 2004

[24] D. Balasankra, K. Vanilarasu, P. Selva Preetha, S.Rajeswari M.Umadevi Debjit Bhowmik Journal of Medicinal Plants Studies Year: 2013, Volume: 1, Issue: 3

[25] Wollgast, J., \& Anklam, Eur. Food Res. Intl., 33, 423-447 (2000),

[26] Ferreira, I. C. F. R., Baptista, P., Vilas-Boas, M., \& Barros, L. Food Chemistry, 100, 15111516(2007)

[27] Pereira, J. A., Pereira, A. P. G., Ferreira, I. C. F. R., Valentão, P., Andrade, P. B., Seabra, R., et al. Journal of Agriculture and Food Chemistry, 54, 8425-8431(2006).

[28] Devendra Kodati, Surendra Pareta and Kartik C. Patra, Annals of Biological Research, 2010, 1 (4) : 234-239.

[29] Brand-Williams W. Food Science Technology (London) 28: 25-30 (1995).

[30] Singleton, V.L., Rossi, J.A. Jr. American Journal of Enology and Viticulture, 16, 144-158 (1965).
[31] Swain, T., and Hillis, W. E., J. Sci. Food Agric., 10, 63 (1959). 